\title{
The effect of context on the perception of music
}

\author{
MARY P. O'BRIANT and W. A. WILBANKS \\ University of Georgia, Athens, Georgia 30602
}

\begin{abstract}
This study examines the idea that cognitive factors may be significant in determining the nature of musical response, arguing against the long-held notion that the meaning of music is denotative in character, that is, embodied in its own internal arrangements of sound. The effects of context on the perception of a Berg "March" was examined by having three groups of subjects rate the piece on a semantic-differential rating scale. Group 1 read a lighthearted passage of prose, while Group 2 read prose chosen to evoke a grim and foreboding mood before listening to the music. Group 3 was the control and read nothing. This manipulation of context resulted in no significant differences between group reactions to the piece, as indexed by the semantic differential.
\end{abstract}

Does music communicate a standard agreed-upon message to all people; that is, does it have denotative meaning? Or is the message itself dependent upon the listener's own perceptual ordering of the incoming sensory information; that is, does it have connotative meaning?

The idea of denotative meaning in music is an ancient and honorable one. The Greek philosopher, Pythagorus, in the 6th century BC, and Plato, in the 5th century BC, both considered musical sounds to be a part of the natural order of things. For Pythagorus, the "music of the spheres" was produced by the planets and stars as they moved through the heavens. Plato kept the notion that the power of music emanated from a higher source, but he also saw it as a potent moral force. Exposure to the proper modes could help a person become discriminating, disciplined, and patriotic, but should the wrong modes have become pervasive, Plato would have feared for the very stability of society.

The denotative conceptualization of the meaning of music persisted into the 19th century with the work of von Helmholtz. In his On the Sensations of Tone, von Helmholtz (1863) tried to explain such musical phenomena as chords, intervals, timbre, scales, and intonation in terms of differences in the sound wave, which registered as discrete sensations of tone. He thought that there was nothing in music that was not first in the tone, and it was here that the ultimate psychology of music must focus.

The shift from a denotative to a connotative conceptualization of the problem began most significantly with the work of Seashore (1938). Although he continued to emphasize the purely acoustic materials of music (e.g., the relationship between such physical characteristics of sound as frequency, amplitude, duration, and form

This study was part of a master's thesis by Mary P. O'Briant. Requests for reprints should be sent to W. A. Wilbanks, Department of Psychology, University of Georgia, Athens, Georgia 30602. to the psychological attributes of pitch, loudness, and timbre), Seashore argued that the meaning of music rested upon the capacity of the listener to organize the physical aspects of music into musical experiences.

Other investigators have looked for variables descriptive of the listener that might account for his response to music. Age, sex, attitude, and education (Lundin, 1967) have all been shown to have significant effects.

However, even as awareness grew of a perceiver's contribution to his own perceptual experience, the idea that the meaning of music is in some degree denotative did not completely disappear. Mursell (1937) suggested an evolutionary perspective on the question: "We, like the lower animals are physically stirred by sound and this is the ultimate reason why music can be a significant carrier of emotion, rather than merely an intellectualized play with tonal relationships" (Mursell, 1937, p. 20).

Schachter (1971) proposed a theory of emotional response to stimulation that could furnish some insight into problems in the psychology of musical meaning. He suggests that an emotional state may be considered to be a function of a state of physiological arousal and a cognition appropriate to that state. Given such a state of arousal, he postulates that one labels and interprets his feelings in terms of the precipitating situation and his apperceptive mass. This theory essentially says that the meaning of music is connotative; that is, "cognitions arising from the immediate situation as interpreted by past experience provide the framework within which one understands and labels one's feelings" (Schachter, 1971 , p. 2). In short, the meaning of music is not determined simply by the acoustic stimulus, but by the interpretation of the resulting state of arousal by the listener.

If we follow Schachter's (1971) line of reasoning and acknowledge the power of music to give rise to a state of physiological arousal, and further, that this state is labeled and found meaningful according to cognitions arising from the listener's apperceptive mass, it follows 
that the meaning of music depends largely upon the context within which the music is heard; and that context should determine the way in which the listener interprets or labels his emotional response.

The measurement of meaning is certainly a task fraught with many philosophical and practical problems. Connotative meaning, for purposes of this study, will be defined as the emotional colorings and images that are evoked in an individual in response to musical stimulations. This is in contrast to the concept of denotative meanirig, which would be the standard agreed-upon meaning of a stimulus object. The basic question is whether the meaning of music is denotative or connotative in character.

Osgood (1957) has developed a powerful measurement tool, the semantic differential, that has been useful in the measurement of connotative meaning. The semantic differential was used in this study, as it seemed an appropriate measurement device for the evaluation of emotional response to musical stimulation.

This study examines the effect of context, defined as the setting in which music is heard, on the subject's interpretation of the state of arousal evoked by the music, as measured by the semantic-differential technique. Our contention is that the context within which a piece of music is heard can have a significant effect upon a listener's labeling of his reaction to that music. In other words, the same piece of music will have a different meaning to a given listener depending upon the context, for it is context that determines the listener's interpretation of his reaction.

The purpose of this study is to look outside the music as well as outside the listener for factors that influence musical responses. We have examined the effect of context, defined as the setting in which music is heard, on subjects' perception of that music.

We still were dealing with a "listener" variable, in that we were interested in the listener's attitude. Attitude has been considered important to perception previously, but little attempt has been made to manipulate it experimentally in a situation of this kind.

If the listener's emotional labeling of a piece of music can be shown to vary according to the context in which that music is heard, assuming that it is context that actually determines the listener's interpretations of his mood, this would argue in favor of the connotative nature of meaning in music. If it is purely denotative in character, the meaning would be unaffected by the manipulation of context.

\section{METHOD}

\section{Subjects}

Forty-eight subjects were drawn from the research partici pant pool of psychology students at the University of Georgia and divided into three groups of 16 subjects. The groups consisted of equal numbers of males and females. All subjects were between the ages of 18 and 22 years.

\section{Procedure}

Testing was done in an austere room that contained only the bare requirements for the procedure: a table, chairs, and a tape player. All subjects were asked to listen with eyes closed to a tape recording of the third movement ("March") of Alban Berg's 3 Pieces for Orchestra, Opus 6, with Antal Dorati conducting the London Symphony Orchestra. The "March" was chosen for its relative obscurity, its varied patterns of rhythms, and its atonality, in other words, for its ambiguous qualities. The piece lasted for $8 \mathrm{~min}$ and $49 \mathrm{sec}$. Subjects were then asked to rate their reactions to the music on each of 30 semanticdifferential rating scales.

Context was manipulated by having Groups 1 and 2 read passages of vivid prose before listening to the music. Group 1 first read a passage from the children's book, Heidi (Spyri, 1945, p. 7) and then an excerpt from a reading on "Joy" in The Communication of Emotional Meaning (Davitz, 1964, p. 102). These were chosen for their ability to evoke a cheerful mood in the subjects. Group 2 first read a passage from Arabian Nights (Lang, 1964, p. 47) and then a selection from The Fall of the House of Usher (Poe, 1845; in Poe, 1970, pp. 216-217). These readings were chosen in order to attempt to establish a grim and anxious mood. Group 3 was the control and read nothing before listening to the music. Following the appropriate experimental treatment, subjects listened to the music and marked their reactions to it on the rating scales.

The particular scale items used in this study were chosen because in factor analysis using Thurstone's centroid factor method, these scales showed consistently high loadings on one of three factors: evaluative, potency, or activity (Osgood, 1957, p. 36). Osgood considers these three factors to be basic to the evaluation of connotative meaning; at least, they appear to be so on the basis of the evidence currently available. The evaluative factor is represented by items such as "good-bad" and "beautiful-ugly." Potency is represented by items such as "large-small" and "heavy-light," while the activity factor is represented by items such as "fast-slow" and "active-passive." Ten scale items were chosen from each of these three factor groups. The items were presented in the sequence evaluation, activity, and potency, and were rotated systematically.

At the end of the test, subjects were asked if the music was familiar to them. Only two subjects responded affirmatively and their rating sheets were discarded. These subjects were replaced. Familiarity with the music would have introduced the possibility that subjects were interpreting their responses to the "March" in terms of previously established cognitive references. This would have had the effect of introducing an additional source of error variance.

Finally, after the rating sheets were returned to the experimenter, the subjects were asked to discuss informally their feelings about the readings and to indicate whether they were, in fact, effective in establishing a definitive mood. All subjects reported feeling their mood altered as a result of reading the prose, and they felt that the change was great enough to be construed as a contextual change. This type of context manipulation is admittedly weak when compared with, say, an actual alteration of the physical environment. It was expected, though, that even this relatively weak manipulation of context would be sufficient to affect perception of the music, thereby resulting in significant differences between groups' responses as a result of experimental treatment.

\section{RESULTS AND DISCUSSION}

Table 1 shows the mean semantic-differential ratings along with the associated standard deviations for Groups 1, 2, and 3 for each scale. The scales are grouped 
Table 1

Mean Semantic-Differential Ratings Grouped as a Function of Scale Dimension

\begin{tabular}{|c|c|c|c|c|c|c|}
\hline \multirow[b]{2}{*}{ Scale } & \multicolumn{2}{|c|}{ Group 1} & \multicolumn{2}{|c|}{ Group 2} & \multicolumn{2}{|c|}{ Group 3} \\
\hline & Mean & SD & Mean & SD & Mean & SD \\
\hline
\end{tabular}

1. good-bad

4. beautiful-ugly

7. sweet-sour

10. heavy-light

13. valuable-worthless

16. kind-cruel

19. pleasant-unpleasant

22. bitter-sweet

25. fragrant-foul

28. sacred-profane

Evaluative Dimension

2. fast-slow
5. active-passive
8. hot-cold
11. sharp-dull
14. angular-rounded
17. calm-agitated
20. red-green
23. ferocious-peaceful
26. tense-relaxed
29. pungent-bland

Activity Dimension

$\begin{array}{llllll}4.6 & 1.59 & 3.5 & 1.57 & 3.6 & 1.45\end{array}$

$\begin{array}{llllll}4.8 & 1.02 & 5.1 & 1.45 & 4.2 & 1.53\end{array}$

$\begin{array}{llllll}5.3 & 1.06 & 5.0 & 1.09 & 4.5 & 1.21\end{array}$

$\begin{array}{llllll}1.9 & 1.95 & 1.8 & .83 & 2.3 & .93\end{array}$

$\begin{array}{llllll}3.1 & 1.15 & 2.9 & 1.34 & 3.5 & 1.51\end{array}$

$\begin{array}{llllll}5.5 & .89 & 5.7 & 1.22 & 5.6 & 1.19\end{array}$

$\begin{array}{llllll}4.8 & 1.74 & 5.0 & 1.34 & 4.1 & 1.60\end{array}$

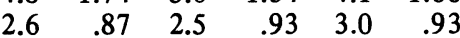

$\begin{array}{llllll}4.9 & .89 & 5.1 & 1.08 & 4.2 & 1.17\end{array}$

$\begin{array}{rrrrrr}4.6 & .89 & 5.1 & 1.08 & 4.2 & 1.17 \\ & 1.21 & 4.5 & .97 & 4.3 & 1.40\end{array}$

\begin{tabular}{|c|c|c|c|c|c|c|}
\hline \\
\hline 3. large-small & 2.3 & .87 & 2.4 & 1.43 & 2.4 & 1.21 \\
\hline 6. strong-weak & 2.0 & 1.46 & 1.9 & 1.20 & 1.8 & 1.04 \\
\hline 9. clean-dirty & 4.1 & 1.03 & 4.2 & 1.56 & 4.5 & 1.15 \\
\hline 12. thick-thin & 2.6 & 1.36 & 2.4 & 1.26 & 2.6 & 1.15 \\
\hline 15. rugged-delicate & 1.8 & .83 & 2.0 & 1.06 & 2.5 & 1.41 \\
\hline 18. deep-shallow & 2.5 & 1.03 & 2.0 & 1.03 & 2.4 & 1.25 \\
\hline 21 . brave-cowardly & 2.6 & 1.02 & 2.3 & 1.39 & 2.6 & 1.46 \\
\hline 24. wide-narrow & 2.9 & 1.68 & 3.3 & 2.05 & 3.3 & 1.21 \\
\hline 27. hard-soft & 2.3 & 1.08 & 2.1 & .81 & 2.4 & .81 \\
\hline 30. bass-treble & 2.9 & 1.52 & 2.4 & 1.36 & 3.8 & 1.48 \\
\hline
\end{tabular}

according to the (1) evaluative, (2) activity, and (3) potency dimensions.

For each scale item, a value of the chi-square statistic was determined. Analysis showed that differences between groups' reactions to the music were not significantly greater than those expected to occur by chance or in the absence of experimental treatment. The Kruskal-Wallis rank-order test also revealed no significant differences between groups.

Could these results indicate that the "March" had much the same meaning to subjects without regard to context, suggesting that meaning is to a large extent denotative in character? Or was the manipulation of context perhaps too weak to be effective?

Finding stronger mood-manipulation devices might increase context effects, although another possibility is that no matter how vivid the context, the music might, indeed, be capable of making a statement too strong to be affected by context. There is no question that associations learned over a period of time can greatly affect the way we feel about a piece of music. A familiar example of this is the welling up of patriotic feeling that most of us experience when we hear the first bars of the "Star Spangled Banner." This would probably happen no matter where we happened to hear the piece.

An attempt was made in this study to control for the problem of learned associations by choosing a piece that was unfamiliar to the subjects. However, it may be that associations are not so easily removed. Perhaps, certain rhythmic patterns, tonalities, or musical styles can evoke strong reactions, even though the particular piece of music may be unfamiliar.

The question of whether the meaning of music is basically denotative or connotative in character is probably too complex for this simple dichotomy to be very useful. Apparently, there is some truth in both positions. Perhaps the most productive way to approach problems concerning the perception of musical stimulation would be to look for the properties found in whole pieces of music, not simply in its isolated parts, that evoke various sorts of emotional responses under varying conditions. This would include learned associations as a variable worthy of experimental consideration. This accurate measurement of feeling responses presents another type of problem for future investigators.

If our original dichotomy of connotative vs. denotative meaning produced no clear-cut support for our hypothesis, it still would seem to have helped us define some of the problems confronting us as we try to understand the factors affecting the perception of a musical stimulus.

\section{REFERENCES}

DAvitz, J. R. The communication of emotional meaning. New York: McGraw-Hill, 1964.

Lang, A. (Ed.). Arabian nights. Santa Rose: Classic Press, 1968. Lundin, R. W. An objective psychology of music. New York: Ronald Press, 1967.

Mursell, J. L. An objective psychology of music. New York: W. W. Norton, 1937.

Osgood, C. E., Suci, G. J., \& Tannenbaum, P. H. The measurement of meaning. Urbana: University of Illinois Press, 1957.

PoE, E. A. The fall of the house of Usher (1845). In E. A. Poe, The great short works of Edgar Allen Poe. New York: Harper \& Row, 1970.

SchACHTER, S. Emotion, obesity and crime. New York: Academic Press, 1971.

SeAshore, C. E. Psychology of music. New York: McGraw-Hill, 1938.

SPYRI, J. Heidi. Kingsport: Grosset \& Dunlap, 1945.

von Helmholtz, H. L. F. [On the sensations of tone, 1863] (A. J. Ellis, trans., 1885). London: Longmans, Green, 1912.

(Received for publication August 31, 1978.) 